\title{
Judicatura y Activismo Judicial ${ }^{*}$
}

\section{Resumen}

El artículo analiza el activismo judicial, a partir de un pretexto que es comentar la obra de Lambert, que ejercerá en Francia una poderosa influencia en materia de revisión judicial de la ley, y que permite extraer algunas "lecciones de un clásico", situadas en la perspectiva contemporánea, a la luz del viejo dogma de la "separación de poderes" y de las decisiones fundamentales acerca del Estado de Derecho y la democracia.

\section{Palabras clave}

Revisión judicial, Judicatura, Tribunal Constitucional, bloque constitucional de derechos, activismo judicial, panjudicialismo, Estado de derecho, democracia.

* Profesor de Derecho Constitucional Universidad de Chile zdmc@zdmcabogados.cl

\section{Prolegómenos}

El Taller de trabajo que nos reúne invita a exponer acerca de los roles de la Judicatura en la política y su inserción en el arreglo institucional que es el régimen político, lo que obliga a esbozar la compleja relación que se da entre Judicatura (Poder Judicial, Justicia Electoral y en especial Tribunal Constitucional) y activismo judicial. En efecto, esta relación plantea como problema el del "gobierno de los jueces», y nada mejor para su abordaje, que un pretexto, un libro clásico del jurista Edouard Lambert, que como buen clásico resiste con extraordinario éxito el paso del tiempo. Pero, además, el «gobierno de los jueces» debe ser un tema central de cualquier reforma judicial que se emprenda, para fijar las definiciones básicas de un Estado de Derecho y de un Estado democrático.

\footnotetext{
* Ponencia inédita a Taller de Trabajo del PAL Instituto Igualdad, Santiago 14 de enero de 2011.
} 
Así, la re-lectura y comentario de una obra clásica del comparatista galo Edouard Lambert: "Le Gouvernement des Juges et la lutte contre la Législation Sociale aux Etats-Unis. La Expérience Américaine du Controle Judiciale de la Constitutinalité des lois" (París, Giard, 1921) vertida a nuestra lengua en el presente año en la colección "clásicos del pensamiento" por el sello editorial de Tecnos, es una buena excusa para dar cuenta de la recepción crítica que le da la cultura jurídica francesa y europea al control judicial de constitucionalidad en su versión angloamericana y, al mismo tiempo, es una buena excusa para abordar críticamente el activismo judicial y sus excesos, fuente de una grave patología en las democracias constitucionales de hoy.

En efecto, Lambert interviene en el debate que el medio francés y europeo tiene acerca del control de constitucionalidad de la ley, poniendo en evidencia los peligros del "gobierno de los jueces" (empleando el término acuñado por Louis B. Boudin en: "Government by Judiciary", publicado en Political Science Quaterly, vol. 26, 1911, y recogido en libro del mismo título de 1932), cuestión que llegó a larvar una crisis político-institucional más tarde con el "New Deal" del presidente F. D. Rooselvet, enfrentando a la Presidencia cansada de un tribunal reaccionario, de los "nueve venerables ancianos", lo que está debidamente documentado. Pero, además, Lambert, quien, en rigor, es comparatista y muy ilustre, un fundador moderno de esa disciplina y fundador en 1920 del Institut de Droit Comparé de Lyon, observa dos problemas basales de un sistema de justicia constitucional: la ilegitimidad democrática de este poder, disfuncional a la democracia, y las dificultades de imponer límites a una Constitución que, prescriptivamente, es lo que los jueces dicen que es; lo que vendría a sustituir la legitimidad democrática del Estado y del orden político por la legitimidad burocrático-judicial. El triunfo de la "soberanía de la Constitución”, Constitución fruto de la lectura de los jueces; "triunfo" en que se refocila, hasta el éxtasis o en el mejor de los casos tocando el "cielo de los conceptos", hoy el neoconstitucionalismo. ${ }^{1}$

El debate acerca del "activismo judicial" es muy propio del derecho y la política de los Estados Unidos de Norteamérica con fuerte resonancia en la opinión pública y los medios de comunicación social; abriéndose de época en época una crítica al activismo, como la de los juristas "progresistas" a una Judicatura reaccionaria que analiza Lambert en su libro, la más contemporánea crítica contramayoritaria (J. Hart Ely), la crítica de "derechas"-neoconservadora (A. Scalia) o la más radical "objeción democrática" (J. Waldron). ${ }^{2}$ En cuanto debate político constitucional norteamericano, siempre desde los albores de la gran república del norte ha habido un debate en torno a los poderes de los tribunales de la Suprema Corte, como lo fue el debate de época entre "federalistas" y "antifederalistas"; independientemente que desde 1803 se asienta con

Toinet (1994), pp. 212-213. También la obra de Pinto (1938). De autores norteamericanos dos textos clásicos que explican el período del New Deal, traducidos al español, de Brent Swisher (1958), pp. 813-843; y de Sutherland (1972), pp. 583-612. Sobre la autocomprensión judicial liberal en lo económico de la Corte Suprema, el libro de un juez de época (New Deal) como Evans Hughes (1971) y más contemporáneo el análisis de las grandes decisiones del Tribunal Supremo en sus grandes épocas, el libro de Berger (1977).

2 Una visión panorámica del debate norteamericano se recoge de las contribuciones de Anaya (2010), pp. 235-261 y García Mansilla (2010), pp. 263-294. Y el divulgado libro en nuestra lengua de Ferreres Comella (1997). 
la doctrina jurisprudencial de la "revisión judicial de legislación”, la primera expresión histórica moderna de la politización de la justicia. Tal "revisión judicial de legislación" es archiconocida en su origen, tanto que el "hercúleo" y longevo Chief Justice John Marshall adquiere dimensiones casi "mitológicas", en una simplemente ubicua y política decisión en "Marbury versus Madison", en la pugna "federalistas" y "antifederalistas" en los albores fundacionales de la gran república del norte.

En un plano conceptual, contemporáneamente, en el medio norteamericano, W. Wayne observa dos dimensiones del activismo: primero, en sede jurisprudencial se reconocen judicialmente ciertos valores que otorgan ciertos derechos a grupos sociales minoritarios, débiles o vulnerables; y, segundo, en la adopción de una posición por los jueces al defender un derecho vulnerado que supone invadir la esfera de competencias de otros órganos políticos o administrativos.

Sin embargo, el debate acerca del "activismo judicial" para situarlo en nuestras coordenadas, debe estar ligado al funcionamiento efectivo de los sistemas de jurisdicción constitucional concentrados, en que este activismo se expresa a través de las sentencias del Tribunal Constitucional, que pasan del control de constitucionalidad de normas (validez) y del obrar de esta Judicatura como "legislador negativo" al obrar como "legislador positivo", como ocurre a través del empleo de sentencias atípicas ${ }^{3}$.

De esta manera, el activismo judicial aparece ligado a la libertad (discrecionalidad) de creación de los jueces, al protagonismo de los jueces, al aggiornamento del servicio de justicia en que sus sentencias, además de heterocomponer el asunto sometido a su competencia, contienen "señales" innovadoras a los demás poderes públicos, a los jueces inferiores u otros órdenes jurisdiccionales, y a la sociedad en general, tendientes a generar un cambio en la legislación, en la jurisprudencia o en las costumbres; "señales" que, según anota Manili, pueden consistir en:

a. Crear derechos, es decir, garantizar la protección de un derecho no enumerado por ser éste considerado de naturaleza constitucional, ampliando así la nómina de derechos protegidos.

b. Ampliar las garantías procesales para la protección de los derechos, sea mediante nuevas garantías o mediante la interpretación amplia de las existentes.

c. Señalarle al Congreso Nacional la necesidad de una reforma legislativa en determinada materia.

d. Allanar los caminos procesales para facilitar u homologar el accionar del Gobierno, a través de un salto de instancias.

e. Convalidar normas de emergencia restrictivas de los derechos fundamentales.

Wayne (1992) pp. 1-13 y (1989) pp. 657-676. También sobre la creación de derecho a través de la sentencia constitucional Gozaíni (1994), pp. 350-358; Sagüés (2008) pp. 75-87; Pizzorusso (1984), pp. 253 y siguientes; Rubio Llorente, Francisco (1988). 


\section{f. Combatir excesos del poder en general ${ }^{4}$.}

En el fondo el "activismo judicial" es parte de un proceso de politización de la justicia, tan propio de las democracias contemporáneas y probablemente un importante indicador de "mala salud democrática". La distinción de Manili, entre un activismo "bueno", conciliable con el garantismo, favorable a los derechos fundamentales, a las acciones de garantía de derechos y a la ampliación de la participación ciudadana, frente a un activismo "malo" en detrimento de los derechos fundamentales y genuflexo con el poder estatal, es un distingo artificioso e interesado, artificioso porque ambos tipos de activismos desbordan el rol de la Judicatura, e "interesado" ideológicamente, en la medida que permite defender o demonizar al activista de "izquierdas" o de "derechas", "progresista"-"liberal" o "neoconservador"-"autoritario"-"neoliberal". Así puestas las cosas el activismo es "bueno" en la medida que me es útil en función de intereses o ideologías, las más de las veces inconfesables.

En nuestro medio, Couso, desde la politología, observa, en una interesante monografía sobre el tema, agudamente: "En este trabajo se aborda la judicialización de la política en países embarcados en procesos de consolidación democrática, específicamente respecto del rol de las cortes en el control de la supremacía constitucional. El interés por este aspecto del fenómeno surge del hecho de que, junto con el retorno o la introducción de regímenes democráticos en decenas de países de América Latina, Europa central-oriental y Asia, la gran mayoría de estas nuevas democracias simultáneamente inauguraron sendos mecanismos de control judicial de la Constitución, convencidos de que ello contribuiría a someter a las autoridades políticas al imperio del derecho (Ginsburg, 2003). Aun cuando las modalidades y mecanismos de revisión judicial de la Constitución difieren entre dichos países, la noción básica de imponer controles jurídicos al poder político en defensa de los derechos humanos, es suscrita por la vasta mayoría de las democracias emergentes ${ }^{5}$. Ante esto, surge la pregunta de si las esperanzas puestas en este tipo de mecanismos para apoyar procesos de consolidación democrática están bien fundadas. El presente artículo pretende comenzar a responder

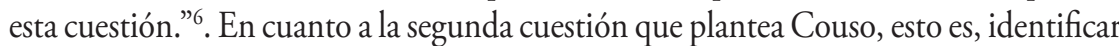
los factores que contribuyen a que emerjan procesos de judicialización de la política, se debe partir por constatar la extensa literatura producida en los últimos años sobre esta materia. Estos trabajos han logrado identificar una serie de elementos que se piensa facilitan el activismo judicial, entre los que se cuentan el trabajo: "La expansión global del poder de la judicatura”, de Tate y Vallinder (1995), en el que se ofrece un resumen de las condiciones que facilitarían la aparición de un activo control judicial de la Constitución: "Los factores que contribuyen a la judicialización de la política son varios: la presencia de un régimen democrático; un sistema de separación de poderes;

Manili (2009)(2010) y Morello (1989) y (1994) p. 119.

Nota al pie de página No 1 del texto que se cita, la que dice: "Por cierto, el que los regímenes autoritarios que las antecedieron hubieran incurrido en brutales violaciones de los derechos de las personas, sin duda contribuyó a la introducción del control judicial de la constitucionalidad de las leyes.".

Couso (2004), p. 30. 
una cultura de derechos (...); partidos políticos débiles o coaliciones de gobierno frágiles que produzcan atochamiento en la elaboración de las políticas públicas (...); y, por último, la delegación a las cortes de autoridad para tomar decisiones en ciertas áreas de las políticas públicas (...) Dicho esto (...) la judicialización de la política puede no darse (...), porque aun bajo una constelación muy favorable de condiciones que la faciliten, el desarrollo real de la judicialización de la política requiere que los jueces tengan las actitudes personales apropiadas, y preferencias fuertes acerca del rol que desempeñan los otros poderes del Estado(...).”7

\section{Judicatura y Separación de Poderes}

\section{Primera tesis: de vueltas a la separación de poderes}

En esta primera tesis, cerrando el abordaje preliminar acerca de qué entender por activismo judicial, es menester subrayar el impacto en la actual jurisprudencia constitucional mediante el socorrido artificio del "bloque constitucional" o "bloque constitucional de derechos". Ello obliga a retomar la pregunta recogida en trabajos anteriores, lo mismo que otros juristas locales al adentrarse en los temas de jurisdicción constitucional y al comentario de jurisprudencia: ¿Quo Vadis Tribunal Constitucional?, pregunta-dilema que nos reconduce a la posición del Tribunal en el balance de poder, el permanente "Scila" del "activismo judicial" y el permanente "Caribdis" del "garantismo procesal", de la autolimitación y deferencia con los poderes públicos democráticos y, en último término, con el pueblo, último depositario del Poder Constituyente.

En un Estado democrático, esta posición del Tribunal Constitucional la fija la Constitución, importando subordinación del Tribunal a ésta y deferencia con los poderes públicos y, de ningún modo, la creación pretoriana del Derecho de la Constitución por quienes están llamados a actualizar e interpretar las normas iusfundamentales en un proceso político abierto y en una comunidad abierta de intérpretes de las mismas normas. Subyace a lo dicho algo elemental: la Constitución, en un sistema de fuentes formales del ordenamiento de raíz democrática, es un subsistema normativo iusfundamental, expresión autodeterminada de las decisiones políticas fundamentales que el pueblo adopta en un tiempo histórico, a través del poder constituyente originario o derivado; y no el fruto de decisiones judiciales de quienes tienen una competencia tasada con "absoluta precisión" en la Constitución para su defensa (STC rol No $1.295 / 2008$, de 6 de octubre de 2009, cons. 12º. En consecuencia, la posición jerárquica de la Constitución y doble dimensión de fuente de fuentes formales y de fuente de un derecho específico (Derecho de la Constitución), enlaza con el principio democrático, tal cual la modélica "Stufenbau Theorie" de la Escuela de Viena (Merkl

Couso (2004), p. 39. 
y Kelsen) nos invita a concebir el edificio estatal. En la lógica del Estado democrático el Tribunal Constitucional está llamado a asegurar la "constitucionalidad de la legalidad", es en sentido figurativo "legislador negativo", no "legislador positivo" ni "constituyente positivo".

Así, por la vía ejemplar en Chile, el lastre ideológico autoritario y neoliberal de la Constitución 1980/2005 vigente, que en su origen es otorgada, no es una buena razón para superar el déficit de derechos y de apertura ideológica a las tradiciones constitucionales democráticas y sociales, a través de la conversión de la Constitución material en Constitución formal operada por medio de un "bloque constitucional de derechos". Ello olvida que lo central es el cambio constitucional, el cual es un precipitado normativo histórico de fuerzas políticas que desde el conflicto y la integración arman los consensos institucionales, admitiendo o tolerando legítimos disensos, en ocasiones disensos profundos.

La política democrática, la deliberación, los espacios de ciudadanía, los partidos, las elecciones, no deben ser sustituidas por decisiones de una "aristocracia togada" (jueces, letrados, funcionarios, profesores de derecho), sin poner en entredicho la democracia misma y el imperio de la ley tan propia de un Estado de Derecho. Esto transforma al activismo judicial en una opción elitista, no indiferente usualmente a la segmentación social que sitúa o coopta a esta aristocracia togada entre las minorías privilegiadas o las pone a su servicio, elitismo negador de la democracia, y tributaria en último término de un elitismo epistemológico desbordante, que atraviesa a fuerza de activismo todas las decisiones públicas.

Por otra parte, el Tribunal Constitucional tiene una posición que determina su relación hacia los poderes públicos democráticos y, en especial, hacia el legislador democrático, posición que importa deferencia y no admitir la justiciabilidad de las cuestiones políticas; velando porque "[...] la ley no vulnere los límites constitucionales, lo que significa [...] garantía de una cierta esfera de autonomía del legislador, que comprende, básicamente, el conjunto de apreciaciones de conveniencia y oportunidad política que lo llevan a la adopción de una u otra fórmula normativa orgánica." (STC rol No $1.295 / 2008$, de 6 de octubre de 2009, cons. 28; en el mismo sentido SSTC roles No 786/2007 y No 896/2007, entre otras).

Un notable auxilio a posicionar al Tribunal Constitucional en el sistema político democrático lo entrega la clásica doctrina de la separación de poderes, ya que esta Judicatura fue pensada, al menos en la teorización de Kelsen, como un conjunto de garantías procesal-constitucionales orientadas a salvar esta separación o reparto de poderes dado el crecimiento y mayor complejidad del Estado. En palabras del barón de Monstesquieu, desde cierta cratología-antropología pesimista acerca del poder político, entiende que "por la disposición de las cosas, el poder detiene al poder", por lo en el esquema trinitario el poder de juzgar es un "poder nulo", y al que se engarzan los poderes de estatuir y de impedir. El poder de estatuir es la prerrogativa de ordenar por su propia cuenta, o de corregir, enmendar, rehacer lo que otro ha hecho; y el poder 
de impedir es la prerrogativa de rechazar, y de hacer nulo lo que otro ha ordenado. En esta dialéctica se integra el Tribunal Constitucional, solo revestido de un poder de impedir, y en tal medida un órgano supremo del Estado "menesteroso", autolimitado, cuya autoridad y legitimidad arranca principalmente de sus decisiones. ${ }^{8}$

De este modo, la doctrina de la separación de poderes y la dialéctica poder de estatuir - poder de impedir, son un puntapié de partida de una autocomprensión de Tribunal Constitucional, como tribunal de derecho, instituido para salvar la separación de poderes, y con ello fijar los límites que la autoridad y libertad tienen en un Estado de Derecho; autocomprensión necesaria para que funcionen los mecanismos institucionales correctivos o preventivos de activismo judicial como la autolimitación, deferencia razonada, no justiciabilidad de cuestiones políticas, entre otras. El poder de impedir de Montesquieu es el "legislador negativo" de Kelsen; único poder de los jueces compatible con el Estado de Derecho; y nuestra decisión iusfundamental acerca de la forma política del Estado como república democrática. Al mismo tiempo tal autocomprensión del Tribunal Constitucional, permite no admitir la legitimidad de sentencias atípicas y exige de esta Judicatura el empleo cuidadoso, dimensionando la eficacia y valor normativo, de normas de conducta iusfundamentales en la que cristalicen valores superiores del ordenamiento y principios constitucionales; y de esta manera reconociendo a los poderes públicos democráticos la determinación de significado de tales valores-principios a través de fuentes infraconstitucionales.

Así, la "jurisdicción constitucional” es un sistema de garantías procesal-constitucionales que aseguran el Derecho de la Constitución, entendido como subsistema normativo revestido de supremacía, valor normativo y eficacia normativa, que salvaguarda la "separación" o reparto de poderes en el Estado, y la separación relativa Estado - sociedad civil a través de la técnica de los derechos fundamentales, a través de los derechos de defensa (derechos civiles), la participación del pueblo en el Estado (derechos políticos) y la protección estatal de necesidades vitales básicas (derechos económicos, sociales y culturales). Luego, en términos de Kelsen la "jurisdicción constitucional”, y no solo el control de constitucionalidad, viene a salvar lo que queda del viejo dogma de la separación de poderes después de su quiebra. La distribución de poder político a través de un arreglo institucional que guarde armonía con el Estado de Derecho y la democracia como forma de organización. En este salvataje de la separación de poderes (horizontal y vertical, según corresponda), en una democracia moderna son las minorías las que hacen uso de ese resorte de defensa de la Constitución, mediante acciones y procesos, ante una Judicatura de derecho, independiente e imparcial. ${ }^{?}$ 


\section{Segunda tesis: Deferencia del Tribunal Constitucional al Poder Judicial}

Como hemos dicho insistentemente, la jurisprudencia del Tribunal Constitucional es reflejo de dos autocomprensiones acerca de su posición y legitimidad, aunque tiende a prevalecer una autocomprensión adscrita teórica e ideológicamente a los conocidos tópicos del neoconstitucionalismo. Las aporías de la jurisprudencia reciente del Tribunal Constitucional, junto al peligro de un "activismo judicial" creador pretoriano de derechos humanos-fundamentales ("bloque constitucional de derechos") a partir de una esencialidad neoiusnaturalista, también plantea un problema en la relación que esta Judicatura debe tener con los tribunales ordinarios y especiales del sistema judicial, en especial la relación abierta por el binomio legalidad-constitucionalidad, y abren una incógnita, como lo hemos destacado en otro lugar, acerca del empleo futuro de la "cuestión de inaplicabilidad" por los jueces.

Esta incógnita deriva de los desincentivos, en orden a entablar "cuestiones de inaplicabilidad" por los jueces, que la jurisprudencia del Tribunal en Chile produce en la medida que, por una parte, reafirma la vinculación primaria de los tribunales del fondo al principio de legalidad, en un sistema de fuentes en el cual aún la ley es la fuente primaria del ordenamiento jurídico y, por otra, contradictoriamente, al ampliar el parámetro del control de constitucionalidad, al menos implícitamente afirmando un "bloque constitucional de derechos", a través del artículo $5^{\circ}$, inciso segundo, de la Constitución y su reenvío a derechos humanos de fuente convencional, limita severamente las posibilidades de que los tribunales del fondo realicen una hermenéutica de la ley conforme a la Constitución. Al mismo tiempo, se limita a los tribunales del fondo en orden a tratar a los tratados internacionales como fuentes infraconstitucionales, que importen una fuente apta para una mejor protección de derechos fundamentales y derechos humanos, cuando tales tratados no requieran transformación o desarrollo de derecho interno, al estar dotados en sus disposiciones de densidad normativa y autoejecutividad necesarias, y gocen en esta perspectiva de una aplicación preferente frente a fuentes formales infraconstitucionales, resolviendo así el conflicto de normas, e interpretando derechos conforme a reglas o principios que aseguren su más plena eficacia.

En términos simples, destruir la Constitución formal o Derecho de la Constitución, imponiendo una Constitución material, bajo la forma de "bloque constitucional de derechos", no sólo quiebra los principios ordenadores de las fuentes y el principio democrático, sino que genera una doble clausura.

Tal doble clausura se produce del modo siguiente: primero en relación a la separación, entre el campo de la legalidad propia de la competencia de los tribunales del fondo y el campo de la constitucionalidad propio del Tribunal Constitucional, se produce la clausura de una sana o vivificante constitucionalización del obrar jurisprudente de los tribunales del fondo utilizando la técnica hermenéutica de la interpretación conforme a la Carta Política de la ley y las fuentes del derecho que utilizan en sus decisiones; en la medida que el derecho constitucional material engulle los tratados o los "de- 
rechos" de los tratados internacionales de derechos humanos ratificados y vigentes. Segundo, también clausura el proceso de afianzamiento en nuestra cultura jurídica, de una nueva cultura garantista, paradigma que permita a estos tribunales (y jueces) utilizar los tratados internacionales de derechos humanos, como fuentes extraordinem incorporadas al ordenamiento jurídico. El "bloque constitucional de derechos" incorpora a la Constitución material a los tratados internacionales e insufla el parámetro del control de constitucionalidad que emplea el Tribunal Constitucional, utilizando para ello incorrectamente la garantía institucional del artículo $5^{\circ}$, inciso segundo, de la Constitución y, de este modo, sustrae tales tratados del campo de la legalidad o decisión de los tribunales del fondo.

En este sentido se hace necesario destacar una reciente jurisprudencia de la Sala Constitucional de la Corte Suprema en Chile alejada de la ambivalencia del Tribunal Constitucional que, con motivo de la incorporación del Convenio No 169 de la Organización Internacional del Trabajo sobre pueblos indígenas, no recurre a mecanismos de conversión de éste en parte integrante de la Constitución material como "bloque constitucional", sino que lo trata como una fuente formal de derecho internacional convencional extraordinem sometida a un principio de aplicabilidad y que debe ser armonizado en su inserción en el derecho interno con las fuentes formales intraordinem, y en todo caso subordinada a la Constitución. Ejemplarmente la sentencia de la Corte Suprema rol No 4078/2010 de 14 de octubre de 2010, señala:

"SEGUNDO: Que cabe destacar a su vez que la consulta a los pueblos interesados que prevé el numeral $1^{\circ}$ del artículo 6 del Convenio tiene por finalidad arribar a un acuerdo acerca de las medidas propuestas, pero jamás dicha forma de participación podría constituirse en una consulta popular vinculante ni afectar las atribuciones privativas de las autoridades que la Carta Fundamental determina. La soberanía, conforme lo dispuesto en el artículo $5^{\circ}$, reside esencialmente en la Nación y se ejerce a través del plebiscito y elecciones periódicas y por las autoridades que la propia Constitución establece, y "ningún sector del pueblo ni individuo alguno puede atribuirse su ejercicio".

Lo anterior significa que los pueblos indígenas, al igual que el resto de los habitantes de este país, están sometidos al ordenamiento constitucional vigente, sin que se les hayan transferido potestades que impliquen, en los hechos, un ejercicio de la soberanía. Sí se les reconoce el goce de determinados derechos que quedan comprendidos, como se ha dicho, dentro de los ámbitos que define nuestro texto constitucional; [...]”.

"CUARTO: Que las normas antes transcritas demuestran que la participación consultiva contemplada en el Convenio no conlleva dotar a los pueblos indígenas de poderes o potestades públicas, sino consolidar el derecho que les asiste a ser consultados en las materias que les atañen;

QUINTO: Que en concordancia con lo antes descrito, el artículo 34 del Convenio N $^{\circ}$ 169 contiene una norma que flexibiliza la incorporación de dicho tratado internacional al derecho interno, disponiendo que "La naturaleza y el alcance de las medidas que se 
adopten para dar efecto al presente Convenio deberán determinarse con flexibilidad, teniendo en cuenta las condiciones propias de cada país";

SEXTO: Que este principio de aplicación del tratado necesariamente implica que para el cumplimiento de sus normas cada Estado deberá tomar en consideración las condiciones de cada cual y sus propias regulaciones, tendiendo a la compatibilización de las normas internas con los principios que inspiran el Convenio a fin de lograr la adecuada materialización de éstos; [...]".

La jurisprudencia reciente citada fragmentariamente, contrasta con la ambivalencia del Tribunal Constitucional en materia de "bloque de constitucionalidad". Con todo, esta criticada orientación jurisprudencial o ambivalencia del Tribunal, cierto es que aún en pañales o larvaria, es prisionera de la suma de muchas patologías que aquejan a la jurisdicción constitucional, el "activismo judicial”, el cual en la demarcación de los campos de la legalidad y constitucionalidad, y vinculaciones de los jueces al principio de legalidad y a la Constitución, termina siendo muy poco deferente con los tribunales del fondo y, por cierto, con los poderes públicos democráticos o el pueblo como depositarios del Poder Constituyente.

En especial el activismo judicial del Tribunal Constitucional es muy poco deferente con el Poder Judicial, el cual está enderezado, en ejercicio de su "potestad conservadora", a la tutela de derechos fundamentales a través del proceso de amparo ordinario y a la tutela de los derechos humanos en general, tutela judicial restauradora o reintegrativa que utiliza como derecho material el Derecho de la Constitución, la legislación y los tratados internacionales de derechos humanos ratificados y vigentes.

\section{Tercera tesis: Prospectiva}

Por último, la reciente y contradictoria jurisprudencia acerca del "bloque constitucional de derechos" contribuye a deslegitimar al Tribunal Constitucional, un tribunal de derecho, llamado a insertarse en el sistema judicial con deferencia hacia el Poder Judicial y la Justicia Electoral, ya que, como lo indica la Judicatura Constitucional, la decisión acerca de conflicto de normas, integración e interpretación de normas legales corresponde exclusivamente a los tribunales creados por ley y, tratándose del orden judicial, el órgano llamado a unificar la interpretación de la ley es la Corte Suprema (STC rol No 1.295/2008, de 6 de octubre de 2009; STC rol No 810/2008, cons. 9o; y SSTC roles No 513/2006, No 980/2007, No 1.201 y No 1.240). El Tribunal Constitucional encuentra su legitimidad instrumental en la actualización a través del proceso constitucional del Derecho de la Constitución, por lo que sus decisiones o sentencias son claves en tal legitimidad, deben ser fundadas, consistentes y comunicables a los poderes públicos, a los justiciables y a la opinión pública. Luego, más allá del consenso-disenso que planteen las sentencias del Tribunal en la opinión pública, en la academia y en el foro, las que nutren a la doctrina y al debate constitucional, sí 
cabe esperar de estas decisiones una cierta consistencia y que permitan abrir un puente entre legalidad y constitucionalidad.

Sin embargo, prospectivamente estas orientaciones jurisprudenciales pueden cambiar, pero se instalan en un contexto político-institucional de pasado y presente en que esporádicamente el Tribunal Constitucional emerge como un actor del proceso político, dueño o creador pretoriano deus ex machina de su competencia, erigido en custodio supremo de la Constitución y de su "sistema material de valores" obra de un Poder Constituyente autoritario en lo político y neoliberal en lo económico, refugiado en un inocultable originalismo (textualista o intencionalista) y que realiza una lectura de la Ley Fundamental desde un anacrónico horizonte ideológico-valórico (neo) iusnaturalista o principialista, que verbigracia le permite la conversión de derechos humanos en derechos fundamentales, por una especial alquimia: la esencialidad-fundamentalidad de los derechos que emanan de la "naturaleza humana".

Ciertamente, se abre hoy un compás de espera y dialécticamente cabe abrigar la esperanza de que se resuelva la jurisprudencia del Tribunal Constitucional por la conciliación de legalidad y constitucionalidad, en la que los jueces tienen vía franca para acceder a esta Judicatura, vía cuestión de inaplicabilidad, una vez agotadas las posibilidades de interpretación conforme a la Constitución y dispuestas las fuentes formales del ordenamiento destinadas a heterocomponer el conflicto desde las coordenadas de una cultura garantista.

Asimismo, cabe esperar que prime en el Tribunal Constitucional una autocomprensión de este órgano como un tribunal de derecho, con una posición institucional orientada al balance de poder desde una competencia tasada en la Constitución, interactuando desde la deferencia y autolimitación con los poderes públicos democráticos e integrando armónicamente el "sistema judicial", poseedor de una legitimidad instrumental y, por ende, precaria en una "democracia constitucional".

No se trata en esta tesis prospectiva de criticar el activismo judicial y defender la apoliticidad y asepsia ideológica de la Judicatura en general y del Tribunal Constitucional en particular, lo que probablemente es una ingenuidad y no soporta la prueba de fuego de la facticidad. Se trata simplemente de situar a la Judicatura y al Tribunal Constitucional, en su posición o lugar en el Estado de Derecho y en el Estado democrático, posición o lugar que debe ser coherente con su propia autocomprensión. El Tribunal Constitucional tiene un lugar en la siempre inacabada empresa o lucha por asegurar el imperio del derecho.

\section{Conclusiones: las Lecciones de un Clásico}

En este apartado final, rememorando un título de Bobbio recogido en su "Teoría general de la política", estimo apropiado compendiar en largas citas "las lecciones de un clásico", ya que la obra de Lambert a que nos referimos en el proemio es un clásico, 
goza de la lozanía de ideas que resiste el paso del tiempo, es fuente inagotable de ideas y nos advierte acerca de los peligros del panjudicialismo, del activismo judicial, y en particular de lo que hoy denominamos "neoconstitucionalismo".

En efecto, el notorio nexo de la Judicatura y los jueces con las ideologías, las culturas jurídicas, el origen social o de clase de éstos y el nexo de su producción jurisprudencial con otros poderes públicos como el Gobierno y el Congreso Nacional son la demostración palmaria de que estamos en presencia de judicaturas no neutrales.

De modo explícito, lo plantea Lambert al afirmar:

"Tanto en el seno de cada Estado como dentro del Gobierno federal pasa a ser al mismo tiempo el órgano del establecimiento y el instrumento de ejercicio de la supremacía política del poder judicial. Pretende asegurar a la más conservadora de las tres ramas del gobierno los medios para regular, filtrar y frenar la actividad de las otras dos ramas coordinadas, pero, sobre todo, la actividad de la más inquieta y de la más audaz de ellas: la legislativa. La experiencia adquirida después de cuarenta años en los Estados Unidos nos aclara el funcionamiento práctico de esta segunda forma del control judicial de la constitucionalidad de las leyes -la única de que podría tratarse en un Estado centralizado como Francia-, y nos permite sopesar los méritos y los defectos del sistema de gobierno del que esta segunda forma constituye la clave de bóveda. ¿En qué sentido se inclina la balanza? ¿Hacia el lado de las ventajas o hacia el lado de los inconvenientes? Esta es una cuestión que dejo en manos de los lectores para que ellos decidan. Les he presentado ante sus ojos las piezas del dossier y, en particular, los testimonios irrecusables que constituyen las sentencias constitucionales de los tribunales de justicia americanos. Son los lectores quienes deben juzgar ahora." ${ }^{10}$

El mismo Lambert advierte acerca del nexo que la Judicatura y las instituciones tienen con las tradiciones de un país:

"Aquellos lectores que piensen que la terrible crisis interior que estamos atravesando no se puede superar más que mediante una persistencia inflexible en nuestras tradiciones económicas del siglo XIX, encontrarán en la meditación del ejemplo americano excelentes razones para justificar su creencia instintiva en las virtudes del control judicial de las leyes. Demostrarán con los hechos la perfecta aptitud de esta construcción original de la práctica americana para suministrarnos, mediante su transplante a Francia, el robusto corsé de hierro que ellos consideran indispensable para reforzar a los ejecutivos vacilantes y agrietados de nuestra organización social y reprimir las fuerzas indisciplinadas, desencadenadas por los contragolpes de la guerra que tienden a desbordarlas y a hacerlas estallar. Para defender el orden moral existente contra los posibles desfallecimientos y espíritu de concesión de los futuros legisladores, no se podría, en efecto, recurrir a guardianes más vigilantes y más tenaces que los jueces. Pues los tribunales de justicia 
reflejan la mentalidad media de la profesión jurídica, que en todos los tiempos y en todos los lugares ha sido siempre la mentalidad social menos permeable a los fermentos revolucionarios o incluso reformistas.".

También Lambert nos llama la atención acerca del espíritu de cuerpo de una "aristocracia togada" que ejerce poder político:

"Podría añadir que el jurista aporta a la defensa de sus dogmas tradicionales tanta más energía e intolerancia, cuanta más conciencia tiene de estar luchando, no por la salvaguarda de vulgares intereses personales, sino por la salvaguarda de su fe y de su ideal profesionales. Individualmente, juristas extraviados en las filas de los partidos de vanguardia, pueden dejarse arrastrar un instante por la excitación de la batalla a desarrollar unas ideas utópicas o reformistas. Pero apenas se han lanzado a sus estudios profesionales vuelven instintivamente al culto de tradicionalismo como a su vocación corporativa y a su razón de ser social. La influencia de la educación y del medio ambiente, la disciplina ejercida por el miedo reverencial a la opinión de los colegas y de los fieles, la aptitud del espíritu de cuerpo a doblegar a los recién llegados a su regla uniforme de conducta se manifiestan con tanta energía sobre este sacerdocio del derecho que es la magistratura, como sobre cualquier otro cuerpo clerical. Muy expresivo es, a este respecto, el ejemplo americano. Jueces de Estados abiertos a la elección popular desplegaron en la lucha contra los audaces de la legislación obrera y social un ardor que al menos iguala al que aportaron los jueces reclutados mediante nombramiento gubernamental, como es el caso de la judicatura de Massachussets o la judicatura federal. Los abades Guitrel de la magistratura americana apenas están instalados en su asiento como magistrados, se ven ya rodeados por la gracia sacerdotal y sienten la necesidad de recuperar, mediante la ortodoxia y la rigidez de su actitud, las concesiones al modernismo y las promesas de tolerancia que han tenido que hacer para obtener la investidura del jefe del partido predominante y la designación del sufragio universal. Con más razón, se puede creer que nuestros jueces, si fueran llamados a la misma función de vigilantes constitucionales, la cumplirían con la misma vigilancia, ellos que no corren peligro de dejarse perturbar por el recuerdo de promesas electorales o por las preocupaciones de una reelección.”.

En particular, a la hora de abordar el control judicial de constitucionalidad de las leyes, Lambert plantea el grado en que la producción jurisprudencial puede ser retardataria y comprometida con el statu quo:

"El control judicial de la constitucionalidad de las leyes, con sus dos complementos: la interpretación de las leyes al modo americano y el gobierno a través de requerimientos, es sin duda el instrumento de estática local más perfeccionado al que actualmente se puede recurrir para embridar la agitación obrera y detener al legislador en la pendiente resbaladiza del intervencionismo económico. 
El control judicial de la constitucionalidad de las leyes tiene la ventaja de presentarse a primera vista bajo una presentación modesta y bajo unas medidas que descartan la desconfianza de aquellos cuya agitación pretende dominar. Si algunos hablan de incluirla en nuestra constitución, es por exceso de escrúpulo. A decir verdad, esto no es necesario, porque esto no figura en ninguna parte en el texto oficial de la constitución federal americana. Se desarrolló como una de las atribuciones naturales de la función judicial. Las propuestas de ley presentadas en su favor ante la cámara de diputados francesa no tenían otro objetivo que recordar a los jueces el ejercicio de uno de los deberes normales de su magistratura, que bajo la influencia de tradiciones anticuadas de los tiempos revolucionarios, ya no estaban habituados a cumplir. No se trata de retocar la constitución de 1875, sino de darle más vida y realismo reprimiendo las violaciones flagrantes de que podrían ser objeto sus textos formales.”.

También Lambert, terciando en el debate francés de época que contrapone a primeras figuras como grandes juristas como L. Duguit y R. Carré de Malberg, escépticos en este campo, G. Jézè y M. Hauriou, favorables al control judicial de constitucionalidad, entre otros, sugiere admitir en el control de constitucionalidad la parte dogmática de la Constitución, con independencia del modelo de jurisdicción constitucional que se elija, sea el americano o el europeo continental:

"Admitido este punto de partida, será necesario a continuación que el control de la constitucionalidad, para entrar efectivamente en acción, se aplique, como lo exigían las propuestas de Charles Benoist y Jules Roche, a la defensa de los principios de la Declaración de los derechos humanos y del ciudadano. Pues no se concibe cómo el legislador podría violar la constitución, que no ha previsto directamente límites a la competencia de éste, si no es por intermediación de los principios de la Declaración de 1789-1791, considerados como normales en todas las constituciones de Francia y en todos los sobreentendidos de las mismas. Extensión que a primera vista no parece que pueda inquietar a los elementos evolucionistas de la opinión pública, ya que tiende a realizar de forma más eficaz la tarea que se ha asignado una asociación de la que no se podrían sospechar opiniones exageradamente conservadoras, la Liga de los Derechos Humanos, e intenta transformar el credo político, de cuya recomendación se sirve esta liga, en parte integrante de nuestro derecho positivo.".

Precisa en este mismo orden de ideas Lambert, el alcance del control judicial de constitucionalidad de la legislación anclada en la parte dogmática:

"La custodia de la Declaración de 1789-1791 suministrará a nuestra magistratura los mismos recursos que las due process clauses de las constituciones americanas suministraron a los jueces de los Estados Unidos para el establecimiento de un control sobre la racionalidad y la oportunidad de las leyes. Para deducir de aquí, contra la legislación obrera o social del futuro, un conjunto tan imponente de condenas constitucionales por causa de la violación de las garantías prometidas 
a la libertad individual, como el que contiene el case law constitucional americano, no tendrá siquiera necesidad de imponer a la palabra libertad el trabajo de interpretación fecundante a que han tenido que dedicarse los jueces de los Estados Unidos.”.

Con todo, Lambert se da el lujo de recoger observaciones críticas respecto de los efectos que para Francia acarrea el control de constitucionalidad de legislación, en los términos siguientes:

"El día en que los jueces franceses conquisten, por su parte, el control de la constitucionalidad de las leyes, encontrarán en nuestra Declaración de los derechos todas las piezas constitutivas del instrumento de cuatro cuerdas que he descrito con el nombre de due process of law y que ha servido a los jueces americanos para someter a los poderes legislativos bajo su supremacía. El mismo juego paciente y subrepticio de las decisiones constitucionales, que ha permitido a la jurisprudencia americana en 1883 y 1900 encerrar la legislación dentro de una red cada vez más densa de limitaciones constitucionales, permitirá sin duda a la legislación francesa llegar en el mismo plazo a maniatar también sólidamente al legislador francés. Las masas obreras, en principio indiferentes a este trabajo en apariencia demasiado técnico de la interpretación constitucional y tranquilizadas, además, sobre su destino por las flamantes etiquetas -constitución, declaración de los derechos, derechos individuales, derecho natural, ley fundamental del país- pegadas sobre el muro de la valla de la obra judicial, no comenzarían, como sucedió en América, a inquietarse seriamente por razón de las pegas aportadas a su propaganda reformadora por el muro de contención constitucional levantado detrás del vallado de derecho natural, hasta el momento en que este muro hubiera alcanzado un grado de consolidación bastante avanzado para poder resistir incluso una subida semejante a la que tuvo lugar en Estados Unidos durante la segunda década del siglo XX bajo la forma de agitación a favor del recall."

Finalmente, Lambert advierte acerca de los costes que para el sistema institucional e incluso para el Poder Constituyente puede tener el gobierno de los jueces y, específicamente, el control de constitucionalidad de las leyes:

"El control judicial de la constitucionalidad de leyes es todavía más tenaz que insinuante. Con cierta vigilancia, como han mostrado los legisladores franceses desde la Revolución hasta estos últimos tiempos, se puede impedir que este control se introduzca en las constituciones. Pero una vez que ha penetrado en ellas, no se podría mantenerlo en ellas con un papel limitado ni extirparlo por las vías pacíficas constitucionales. El ejemplo americano es la mejor prueba de que, tan pronto como este control deja de ser un simple mecanismo de vigilancia judicial sobre el legislativo y el ejecutivo, transforma radicalmente la naturaleza misma de la constitución que lo acoge. A las constituciones rígidas levantadas por las convenciones o las asambleas constituyentes las sustituye por unas constituciones judiciales, de una flexibilidad extrema, que se enriquecen constantemente con elementos 
nuevos mediante el juego de la litigación constitucional. O, para ceńirnos todo lo posible a los hechos, este control incorpora a la antigua constitución popular una constitución judicial, más nueva y más viva, que poco a poco recubre y asfixia bajo sus frondosidades exuberantes la obra primitiva de los constituyentes.

Al dar a los tribunales de justicia el derecho a hablar en nombre de la Constitución $y$, por consiguiente, a desarrollarla y a completarla, el control judicial le entrega el medio de vigilar la resistencia de cada uno de los eslabones de la supremacía judicial y, en caso de que alguno de ellos cediera, sustituirlo por eslabones nuevos y más sólidos que puedan resistir incluso a las empresas que pudieran estar tentadas a socavar la supremacía judicial a través del órgano oficial de la revisión de la Constitución, pues este control les confía la interpretación tanto de las leyes constitucionales elaboradas por este órgano de modificación, como de las leyes ordinarias y, al contacto con el control de constitucionalidad, la interpretación judicial adquiere tal libertad de movimientos, que se trata de un verdadero poder de destrucción y de reconstrucción.".

Para concluir, es menester observar que estas lecciones de un clásico deben ser tomadas en cuenta a la hora de asumir un compromiso teórico-metodológico e ideológico, explícito o implícito, con el panjudicialismo y activismo judicial. Ciertamente, el activismo judicial no se acopla bien con el Estado de Derecho y el principio de legalidad y de suyo con el principio de separación de poderes. Pero hasta allí ese es un desacoplamiento con un modelo de Estado de Derecho eminentemente liberal. Lo grave a mi juicio, es que tal desacoplamiento también se produce con el Estado democrático, ya que el "gobierno de los jueces" debilita la política democrática, anula o reduce los espacios de deliberación pública, somete a revisión las políticas públicas y las decisiones políticas de los poderes públicos. El "gobierno de los jueces" pretende en suma que decisiones políticas importantes y menos importantes las adopte la "aristocracia de toga" y no los "poderes públicos" democráticos que en la disputa con el voto popular han obtenido la legitimidad necesaria para impulsar agendas políticas, programas gubernamentales y políticas públicas, "poderes públicos" cuyos servidores son de cara al cuerpo electoral o las instituciones responsables jurídica y políticamente.

Conecta con el panjudicialismo y el activismo judicial, el contemporáneo neoconstitucionalismo, que difícilmente podría ser catalogado de nueva matriz teórica, pero que posee seńas de identidad tales como las siguientes: expansión competencial de la Judicatura, constitucionalización del derecho, difusión de una concepción axiológica de los derechos fundamentales, progresiva consolidación de reglas de composición de conflictos (principio de ponderación), afianzamiento de principios que amplían el escrutinio judicial de la actividad pública (principio de proporcionalidad), renovación de principios y valores del derecho, crisis de la soberanía nacional frente a la globalización, apertura al derecho internacional y al derecho comparado, control de convencionalidad, entre otras. El vector común del neoconstitucionalismo es, superando o intentando superar el (paleo)positivismo, materializar la Constitución, destruir la constitución formal, asignándole crecientemente poder a los jueces. 
Si escucháramos las lecciones de una obra clásica como la de Lambert, podríamos sostener hoy, 90 años después, que el panjudicialismo, el activismo judicial, son direcciones teórico-prácticas y características de la autocomprensión de las judicaturas que conducen al "gobierno de los jueces" y tal gobierno puede ser de "derechas" o de "izquierdas” y me temo que, las más de las veces, la rematerialización de la Constitución sirve ideológicamente al statu quo.

Lo anterior explica que el neoconstitucionalismo pueda ser también de "derechas" o de "izquierdas", "neoliberal"-"neoconservador" o "liberal"- "progresista", en la medida que en cuanto refrito ideológico y teórico neoiusnatutralista puede servir al cambio o al statu quo.

En un Estado democrático, estas posiciones ideológico-políticas, y la competencia por el voto popular de los partidos, e incluso la despreciada partidocracia, es el escenario de la política democrática, como lo es las de consensos y disensos, y en general la participación del pueblo y deliberación pública.

Las "lecciones de un clásico", como lo es la obra de Lambert, son que los cambios políticos y el cambio social y económico debe tener como protagonista al pueblo como sujeto histórico-político y depositario del poder constituyente, y a través de los arreglos constitucionales correspondientes el mismo pueblo debe definir el signo político-ideológico que de tiempo en tiempo cada comunidad política determine. Encomendar tales decisiones o admitir la injerencia en tales decisiones a la Judicatura constituye un peligro para la democracia misma. Por ello cualquier reforma judicial debe morigerar los peligros del panjudicalismo y del activismo judicial, en suma del "gobierno de los jueces".

\section{Bibliografía citada}

Anaya, Jorge A. (2010): “La judicial review y la dificultad contramayoritaria”, en Manili, Pablo L., Tratado de Derecho Procesal Constitucional (Buenos Aires, Editorial La Ley) 3 vol., Tomo I, pp. 235-261.

Berger, R. (1977): "Government by Judiciary. The transformation of the fourtheenth Amendment" (Harvard University Press).

Brent Swisher, Carl (1958): El Desarrollo constitucional de los Estados Unidos (Buenos Aires, Edititorial Bibliográfica Argentina).

Couso, Javier (2004): "Consolidación democrática y Poder Judicial: Los riesgos de la judicialización de la política”, en Revista de Ciencia Politica (Vol. XXIV, N²) pp. 29-48. [Fecha de consulta: 4 de noviembre de 2009]. Disponible en: http:// www.scielo.cl/pdf/revcipol/v24n2/art02.pdf

Evans Hughes, Charles (1971): La Suprema Corte de los Estados Unidos (México, FCE). 
Ferreres Comella, Víctor (1997): Justicia constitucionaly democracia (Madrid, Edit. Centro de Estudios Políticos y Constitucionales).

García Mansilla, Manuel J. (2010). "La judicial review y sus nuevos críticos”, en Manili, Pablo L., Tratado de Derecho Procesal Constitucional (Buenos Aires, Editorial La Ley) 3 vol., Tomo I, pp. 263-294.

Gozaíni, Osvaldo Alfredo (1994): La justicia Constitucional (Buenos Aires, Depalma).

Henríquez Viñas, Miriam (2010): “¿Activismo Judicial en la obtención de cobertura adicional para enfermedades catastróficas?”, en Estudios Constitucionales (Año 8, $\mathrm{N}^{\circ} 1$ ), pp. 401-424.

LAMBert, Edouard (I921): Le gouvernement des juges et la lutte contre la législation sociale aux Etats-Unis: L'éxperience américaine du controle judiciaire de la constitutionnalité des lois (París, M. Girad, 1921, traducción citada de Editorial Tecnos, Madrid, 2010).

Manili, Pablo Luis (2006): "El activismo (bueno y malo) en la jurisprudencia de la Corte Suprema”, en Revista La Ley (Tomo 2006-D) pp. 1285 y ss. [Fecha de consulta: 4 de noviembre de 2009]. Disponible en: http://www.pablomanili.com. ar/art_activismo.php

(2009): "El activismo en la interpretación constitucional de la actual Corte Suprema”. Ponencia presentada a Congreso Argentino de Derecho Constitucional, XIX Encuentro de Profesores de Derecho Constitucional, realizado en San Miguel de Tucumán, Tucumán, Argentina, durante los días 26, 27, 28 y 29 de agosto de 2009. [Fecha de consulta: 4 de noviembre de 2009]. Disponible en: http://www.derechotucuman2009.com.ar/descargas/2_005_PABLO_MANILI.doc

Montesquieu, Charles de Secondat, barón de (1985): Del espiritu de las Leyes (México, Editorial Porrúa, $6^{\circ}$ edición).

Morello, Augusto Mario (1989): La Corte Suprema en Acción (Buenos Aires, Editorial Platense-Abeledo Perrot).

Morello, Augusto Mario (1994): El Proceso Justo. Del Garantismo Formal a la Tutela Efectiva de los Derechos (Buenos Aires, Abeledo Perrot).

Pinto, Roger (1938): "La Cour Supréme et le New Deal” (París, Sirey R.).

Pizzorusso, Alessandro (1984): "El Tribunal Constitucional italiano", en A.A.V.V. Tribunales Constitucionales europeos y derechos humanos (Madrid, CEC).

Requejo, Paloma (2000): Democracia parlamentaria y principio minoritario. La protección constitucional de las minorías parlamentarias (Barcelona, Editorial Ariel).

Rubio Llorente, Francisco (1988): "La jurisdicción constitucional como forma de creación del derecho", en Revista Española de Derecho Constitucional (No 22). 
Sutherland, Arthur E. (1972): De la Carta Magna a la Constitución Norteamericana. Ideas fundamentales sobre constitucionalismo (Buenos Aires, Tipográfica Editora Argentina).

Toinet, Marie France (1994): El sistema politico de los Estados Unidos (Prefacio S. Hoffmann y traducción G. A. Galardo, México, F.C.E.).

Wayne, William (1989): "The New Awakening: Judicial Activism in a conservative age", en Southwestern Law Journal (Vol. 43, October) pp. 657-676.

(1992): "Two Faces of Judicial Activism", en George Washington Law Review (Vol. 61, N¹) pp. 1-13.

ZúñIga Urbina, Francisco (2008): "Derechos Humanos en la Jurisprudencia del Tribunal Constitucional chileno: apostillas sobre Tratados y Constitución”, en Revista de Derecho Politico ( $\left.\mathrm{N}^{\circ} 71-72\right)$, pp. 787-827.

(2003): Montesquieu y el dogma de la separación de poderes (Santiago, Colección Ideas, Fundación Chile 21).

(1991-1992): "Separación de poderes y Estado de Derecho", en Revista de Derecho de la Pontificia Universidad Católica de Valparaíso (No XIV), pp. 191-199. 